Journal of Agricultural Sciences
(Tarim Bilimleri Dergisi)

\title{
Soil Temperature Prediction via Self-Training: Izmir Case
}

\author{
Goksu TUYSUZOGLU ${ }^{\mathrm{a} *}\left(\mathbb{D}\right.$, Derya BIRANT ${ }^{\mathrm{a}}$ (D), Volkan KIRANOGLU ${ }^{\mathrm{a}}$ (D)

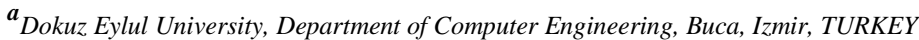

ARTICLE INFO

Research Article

Corresponding Author: Goksu TUYSUZOGLU, E-mail: goksu.tuysuzoglu@ deu.edu.tr

Received: 30 July 2020 / Revised: 06 March 2021 / Accepted: 09 March 2021 / Online: 20 January 2022

\section{ABSTRACT}

This paper proposes a new model, called Soil Temperature prediction via Self-Training (STST), which successfully estimates the soil temperature at various soil depths by using machine learning methods. The previous studies on soil temperature prediction only use labeled data which is composed of a variable set $X$ and the corresponding target value $Y$. Unlike the previous studies, our proposed STST method aims to raise the sample size with unlabeled data when the amount of pre-labeled data is scarce to form a model for prediction. In this study, the hourly soil-related data collected by IoT devices (Arduino Mega, Arduino Shield) and some sensors (DS18B20 soil temperature sensor and soil moisture sensor) and meteorological data collected for nearly nine months were taken into consideration for soil temperature estimation for future samples.
According to the experimental results, the proposed STST model accurately predicted the values of soil temperature for test cases at the depths of 10, 2030,40 , and $50 \mathrm{~cm}$. The data was collected for a single soil type under different environmental conditions so that it contains different air temperature, humidity, dew point, pressure, wind speed, wind direction, and ultraviolet index values. Especially, the XGBoost method combined with self-training (ST-XGBoost) obtained the best results at all soil depths $\left(\mathrm{R}^{2}\right.$ 0.905-0.986, MSE 0.385-2.888, and MAPE 3.109\%$8.740 \%$ ). With this study, by detecting how the soil temperature will change in the future, necessary precautions for plant development can be taken earlier and agricultural returns can be obtained beforehand.

Keywords: Soil temperature prediction, Self-training, Regression, Machine learning, Agriculture, Artificial Intelligence, STST

(C) Ankara University, Faculty of Agriculture

\section{Introduction}

As technology advances, new solutions are emerging to help simplify agriculture and improving productivity and consumer satisfaction with the increased interest in precision agriculture. The applications of modern information technologies, machine learning, and artificial intelligence offer favorable computational as well as analytical solutions by employing data from multiple sources for decision making in the management of crop production (Friedl 2018). Precision agriculture, soil temperature, and climatic parameters have complex inter-relationships and this complex problem can be efficiently solved using machine learning techniques. The estimation of greenhouse gas emission from agricultural soils (Hamrani et al. 2020), evaluation of farm efficiency (Nandy \& Singh 2020), weed classification (Dadashzadeh et al. 2020), plant disease detection (Giraddi et al. 2020), and the determination of the concentration of chemical matters in a grain (Niedbała et al. 2020) are some of the agricultural issues where machine learning is frequently implemented, nowadays.

Soil is of great importance in the terrestrial ecosystem by affecting the physical, biological, and chemical processes. Many studies in agriculture are canalized into this field, especially in terms of the effects of soil moisture and soil temperature on crop yields and plant growth and due to their impact on organic and chemical substances found in soil (Hillel 2005; Yang et al. 2019). Soil temperature plays an important role in agriculture since it is closely related to the myriad events occurring in the soil. It is a very important ecological factor that affects plant life at all stages from seed germination to seedling growth and development. It has a great effect on germination speed and duration. Although other conditions are suitable, if the temperature is too low or too high, there will be little or no germination. If the soil temperature is suitable, biological and chemical activities in the soil continue. These activities stop when the temperature drops and the soil freezes. On the other side, soil resistance to the physical events such as erosion and subsidence can drop dramatically at high soil temperatures. For this reason, factors affecting soil warming and control of soil temperature are extremely important. If we predict further changes in soil temperature, we can develop new strategies in different application areas such as setting up automatic cooling / heating system or irrigation system and determining the planting dates of temperature-sensitive crops etc.

Because of the importance of the subject, various different regression and statistical analysis techniques were proposed considering machine learning such as support vector machines (SVM) (Xing et al. 2018), to estimate soil temperature, and decision tree regression (Pekel 2020) and the least-squares support vector machine (Ren et al. 2019) to predict soil moisture and 
collaborative data mining using the algorithms of local polynomial regression, neural networks, k-nearest neighbor, support vector machine (Anton et al. 2019) to estimate both soil temperature and soil moisture.

The soils of Turkey are divided into three major groups: zonal, intrazonal, and azonal. Zonal soils that are formed by the dissolution of rocks under the influence of climatic conditions and vegetation consist of brown forest soils, podsolic forest soils, Terra-Rossa's, chernozems, brown steppe soils, chestnut steppe soils. Vertisols, rendzinas, and volcanic sandy soils are in the category of intrazonal soils that reflect the characteristics of the bedrock. Alluvial/colluvial soils and loesses are examples of azonal soils that are not dependent on natural factors such as climate and vegetation but are formed due to accumulation by the effect of external factors such as streams and wind (Gönençgil et al. 2016; Akengin \& Dölek 2019).

The soil temperature of Turkey at the depth of $0.5 \mathrm{~cm}$ increases from the Black Sea coast to the Aegean and Mediterranean coasts and decreases continuously from the coastal belt to the mountains and Eastern Anatolia. The lowest underground temperature varies between $-3{ }^{\circ} \mathrm{C}$ and $-6{ }^{\circ} \mathrm{C}$ in the higher parts of Eastern Anatolia. The temperature varying between $1-3{ }^{\circ} \mathrm{C}$ in Central Anatolia rises to $4-6{ }^{\circ} \mathrm{C}$ in the Black Sea, Marmara, and North Aegean coastal belt, and to 9-10 ${ }^{\circ} \mathrm{C}$ in the Southern Aegean and Mediterranean coastal belt. It is between 3-6 ${ }^{\circ} \mathrm{C}$ on the low plains of Southeastern Anatolia. Soil temperature varies between $2-14{ }^{\circ} \mathrm{C}$ at a depth of $100 \mathrm{~cm}$ in winter. The temperature, which is $2-3{ }^{\circ} \mathrm{C}$ in the higher parts of Eastern Anatolia, increases to $8-9{ }^{\circ} \mathrm{C}$ in the Black Sea coastal zone and to $11-13{ }^{\circ} \mathrm{C}$ in the Aegean and Mediterranean coasts. The temperature, which is between $4-6{ }^{\circ} \mathrm{C}$ in Central Anatolia, rises above $10{ }^{\circ} \mathrm{C}$ in Southeastern Anatolia. The soil temperature at $0.5 \mathrm{~cm}$ depth in July, which characterizes the summer period, varies between $20-25^{\circ} \mathrm{C}$ in Eastern Anatolia and $25-30{ }^{\circ} \mathrm{C}$ in Central Anatolia. The temperature, which is around $25^{\circ} \mathrm{C}$ in the Black Sea coastal zone, reaches $30-35{ }^{\circ} \mathrm{C}$ in the Aegean coasts and $35-38{ }^{\circ} \mathrm{C}$ in Southeastern Anatolia. The temperature changes between $13-27{ }^{\circ} \mathrm{C}$ in $100 \mathrm{~cm}$ deep soil in July. The lowest decrease in the soil temperature towards the bottom in July occurs in the Eastern Anatolia and the Black Sea coastal zone, the highest decrease in the Mediterranean and Southeastern Anatolia. As a matter of fact, the temperature decrease at the depth of $0.5 \mathrm{~cm}$ to $100 \mathrm{~cm}$ in July reaches 5 to $7{ }^{\circ} \mathrm{C}$ on the Black Sea coast, 7 to $10^{\circ} \mathrm{C}$ in Central Anatolia and $10^{\circ} \mathrm{C}$ in Southeastern Anatolia (Gönençgil et al. 2016).

Table 1 displays the recent machine learning studies taking soil temperature prediction in Turkey as the main subject. In addition to the past values of soil temperature, meteorological factors such as air temperature, relative humidity, and solar radiation, etc. were generally used as input for the applied models for estimation. The experimental studies were made from 5 $\mathrm{cm}$ to $100 \mathrm{~cm}$ depth in general. The performed method was mostly artificial neural networks (ANN) among them. 
Table 1- Recent studies for soil temperature prediction in Turkey*

\begin{tabular}{|c|c|c|c|c|}
\hline Ref/Study Area & Aim & Data & Methods & $\begin{array}{l}\text { Performance } \\
\text { Measure }\end{array}$ \\
\hline $\begin{array}{l}\text { Alizamir et al. 2020b / The } \\
\text { city of Mersin }\end{array}$ & $\begin{array}{l}\text { Monthly ST prediction at } \\
\text { depths of } 5,10,50 \text {, and } \\
100 \mathrm{~cm}\end{array}$ & $\begin{array}{l}\text { 25-year (1986-2010) } \\
\text { monthly values of AT, } \\
\text { SR, RH, WS, and ST }\end{array}$ & $\begin{array}{l}\text { ELM, } \\
\text { ANN, } \\
\text { CART, and } \\
\text { GMDH }\end{array}$ & $\begin{array}{l}\text { RMSE, NS, } \\
\mathrm{R}^{2}\end{array}$ \\
\hline $\begin{array}{l}\text { Kisi et al. } 2017 \text { / The cities } \\
\text { of Adana and Mersin }\end{array}$ & $\begin{array}{l}\text { Monthly ST prediction at } \\
\text { the depths of } 10,50 \text {, and } \\
100 \mathrm{~cm}\end{array}$ & $\begin{array}{l}\text { 25-year (1986-2010) } \\
\text { monthly values of AT, } \\
\text { SR, RH, WS, and ST }\end{array}$ & $\begin{array}{l}\text { ANN, } \\
\text { ANFIS, } \\
\text { and GP }\end{array}$ & $\begin{array}{l}\text { RMSE, } \\
\text { MARE, NS, } \\
\mathrm{R}^{2} \\
\end{array}$ \\
\hline $\begin{array}{l}\text { Yener et al. } 2017 \text { / All of the } \\
81 \text { provinces in Turkey }\end{array}$ & $\begin{array}{l}\text { Monthly ST prediction } \\
\text { for shallow geothermal } \\
\text { applications at depths of } \\
5,10,20,50 \text {, and } 100 \mathrm{~cm}\end{array}$ & $\begin{array}{l}\text { Monthly values of AT } \\
\text { and ST between } 1960 \\
\text { and } 2015\end{array}$ & $\begin{array}{l}\text { TIR, ANN, } \\
\text { PDV, and } \\
\text { soil heat } \\
\text { calculator } \\
\text { program } \\
\end{array}$ & $\begin{array}{l}\text { Maximum } \\
\text { average } \\
\text { percentage } \\
\text { error }\end{array}$ \\
\hline $\begin{array}{l}\text { Citakoglu } 2017 \text { / } 261 \\
\text { stations all over Turkey }\end{array}$ & $\begin{array}{l}\text { Monthly ST prediction at } \\
\text { depths of } 5,10,20,50, \\
\text { and } 100 \mathrm{~cm}\end{array}$ & $\begin{array}{l}\text { AT, P, and ST values } \\
\text { between } 20 \text { and } 45 \text { years } \\
\text { of data (over the period } \\
\text { from } 1974 \text { through } \\
2010 \text { ) }\end{array}$ & $\begin{array}{l}\text { ANN, } \\
\text { ANFIS, } \\
\text { and MLR }\end{array}$ & $\begin{array}{l}\text { MAE, RMSE, } \\
\mathrm{R}^{2}\end{array}$ \\
\hline $\begin{array}{l}\text { Kisi et al. } 2015 \text { / The city of } \\
\text { Mersin }\end{array}$ & $\begin{array}{l}\text { Monthly ST prediction at } \\
\text { depths of } 5,10,50 \text {, and } \\
100 \mathrm{~cm}\end{array}$ & $\begin{array}{l}\text { 25-year (1986-2010) } \\
\text { monthly values of AT, } \\
\text { SR, RH, WS, and ST }\end{array}$ & $\begin{array}{l}\text { MLP, } \\
\text { RBNN, } \\
\text { and GRNN } \\
\end{array}$ & $\begin{array}{l}\text { RMSE, MAE, } \\
\mathrm{R}^{2}\end{array}$ \\
\hline $\begin{array}{l}\text { Bilgili M et al. } 2013 \text { / The } 7 \\
\text { meteorological stations, } \\
\text { namely, Afyonkarahisar, } \\
\text { Aydın, Denizli, Kütahya, } \\
\text { Uşak Manisa, and Muğla as } \\
\text { the neighboring stations, and } \\
\text { İzmir as the target station }\end{array}$ & $\begin{array}{l}\text { Monthly ST prediction of } \\
\text { a target station only using } \\
\text { the data of neighboring } \\
\text { stations at depths of } 5 \text {, } \\
10,20,50 \text {, and } 100 \mathrm{~cm}\end{array}$ & $\begin{array}{l}\text { Monthly ST data } \\
\text { between } 2000 \text { and } 2006\end{array}$ & $\begin{array}{l}\text { SR analysis } \\
\text { and ANN }\end{array}$ & MAPE, R \\
\hline $\begin{array}{l}\text { Bilgili M } 2012 \text { / Kütahya, } \\
\text { Manisa, Usak, } \\
\text { Afyonkarahisar, Izmir, } \\
\text { Aydın, Denizli, and Mugla }\end{array}$ & $\begin{array}{l}\text { Monthly ST prediction at } \\
\text { depths of } 5,10,20,50 \text { and } \\
100 \mathrm{~cm}\end{array}$ & $\begin{array}{l}\text { Monthly AT and ST } \\
\text { data between } 2000 \text { and } \\
2006\end{array}$ & ANN & MAE, R \\
\hline $\begin{array}{l}\text { Bilgili M } 2011 \text { / The city of } \\
\text { Adana }\end{array}$ & $\begin{array}{l}\text { Monthly ST prediction at } \\
\text { depths of } 5,10,20,50 \text {, } \\
\text { and } 100 \mathrm{~cm}\end{array}$ & $\begin{array}{l}\text { Monthly values of AT, } \\
\text { AP, RH, WS, R, and ST } \\
\text { between } 2000 \text { and } 2007\end{array}$ & ANN & MAPE, R \\
\hline $\begin{array}{l}\text { Ozturk et al. } 2011 \text { / } 66 \\
\text { Turkish state meteorological } \\
\text { service locations }\end{array}$ & $\begin{array}{l}\text { Monthly ST prediction at } \\
\text { depths of } 5,10,20,50 \text { and } \\
100 \mathrm{~cm}\end{array}$ & $\begin{array}{l}\text { Altitude, latitude, } \\
\text { longitude, monthly } \\
\text { values of AT, SD, SR, } \\
\text { AT between 2006-2008 }\end{array}$ & ANN & RMSE, R \\
\hline $\begin{array}{l}\text { Bilgili M } 2010 \text { / The city of } \\
\text { Adana }\end{array}$ & $\begin{array}{l}\text { Monthly ST prediction at } \\
\text { depths of } 5,10,20,50 \text { and } \\
100 \mathrm{~cm}\end{array}$ & $\begin{array}{l}\text { Monthly values of ST, } \\
\text { AT, AP, WS, RH, R, } \\
\text { SR, SD between } 2000 \\
\text { and } 2007\end{array}$ & $\begin{array}{l}\text { LR, NLR, } \\
\text { and ANN }\end{array}$ & MAPE, R \\
\hline
\end{tabular}

*ELM, Extreme learning machine; ANN, Artificial neural networks; CART, Classification and regression trees; GMDH, Group method of data handling; ANFIS, Adaptive neuro-fuzzy inference system; GP, Genetic programming; TIR, Thermal infrared technique; PDV, Philip and de Vries model; SR, Stepwise regression; LR, Linear regression; NLR, Nonlinear regression; RMSE, Root mean square error; NS, Nash-Sutcliffe coefficient; $\mathrm{R}^{2}$, Coefficient of determination; MARE, Mean absolute relative errors; MAPE, Mean absolute percentage error; R, Correlation coefficient; MAE, Mean absolute error; AT, Air temperature; SR, Solar radiation; RH, Relative humidity; WS, Wind speed; P, Precipitation; AP, Atmospheric pressure; R, Rainfall; SD, Sunshine duration.

Differently from the mentioned studies, this is the first study that is performed by one of the semi-supervised learning techniques known as "self-training" in the subject of soil temperature prediction. Semi-supervised learning is a machine learning approach in which there are a small number of samples whose output is known and a large number of samples with unknown labels to develop a classification/regression model during training (Belkin et al. 2006). One of the semi-supervised learning methods is self-training (Zhu \& Goldberg 2009).

A novel model, called Soil Temperature prediction via Self-Training (STST) is proposed. The STST facilitates the capability of temperature estimation for new samples in case there are few numbers of labeled samples to discover the hidden patterns.

This is the first time that the analysis is being reported in detail to determine which regression method provides the most accurate predictions under the self-training framework and the variation in the performances. For this purpose, it compares the self-training versions of machine learning algorithms, including Random Forest (RF), Support Vector Regression (SVR), Knearest Neighbors Regression (KNNReg), Extremely Randomized Trees (ETReg), Decision Tree Regression (DTReg), and Extreme Gradient Boosting (XGBoost). 
This study is also original in that it investigates the performances of the semi-supervised machine learning algorithms on soil temperature prediction with different ratios of labeled data varying from $5 \%$ to $85 \%$ with an increment of 5 . It should be highlighted that this paper is the first to propose a multi-depth self-training learning framework that considers estimating the soil temperatures at five different soil depths $(10,20,30,40$, and $50 \mathrm{~cm})$. It presents a new application of semi-supervised machine learning to provide a smart way of soil temperature prediction. The purpose is to estimate the soil temperature in Izmir, Turkey by investigating the dynamics of the past soil temperature \& soil moisture data and the meteorological data.

\section{Material and Methods}

In this section, the materials used to collect data, the proposed "Soil Temperature prediction via Self-Training" (STST) model, and the machine learning methods used in the experiments are presented.

\subsection{Data collection}

The location of the experimental area is Izmir, Turkey during the dates of 01.09.2019 and 22.05.2020. Izmir is located in the Aegean region of Turkey between the latitude of $38^{\circ} 24^{\prime} 46^{\prime \prime}$ and the longitude of $27^{\circ} 8^{\prime} 18^{\prime \prime}$. It is located in the Mediterranean climate zone and it has hot and dry summers and warm and rainy winters. In the middle latitude zone, it is open to marine effects and has a climate affected by the tectonic characteristics of the coastal Aegean strip and the bay having inland sea character. Depending on the sunshine duration and sufficient amount of rainfall, the soil structure has an agriculturally suitable climate (Turkish State Meteorological Service, 2021). While the yearly mean value of rainfall is $700.2 \mathrm{~mm}$, the yearly mean values of air temperature and soil temperature are $17.6^{\circ} \mathrm{C}$ and $19.8{ }^{\circ} \mathrm{C}$, respectively (Republic of Turkey Ministry of Agriculture and Forestry 2021). Its soil moisture and temperature regimes are xeric and thermal (Bolca et al. 2011; Kapur et al. 2018). Figure 1 shows the study area in the location map.

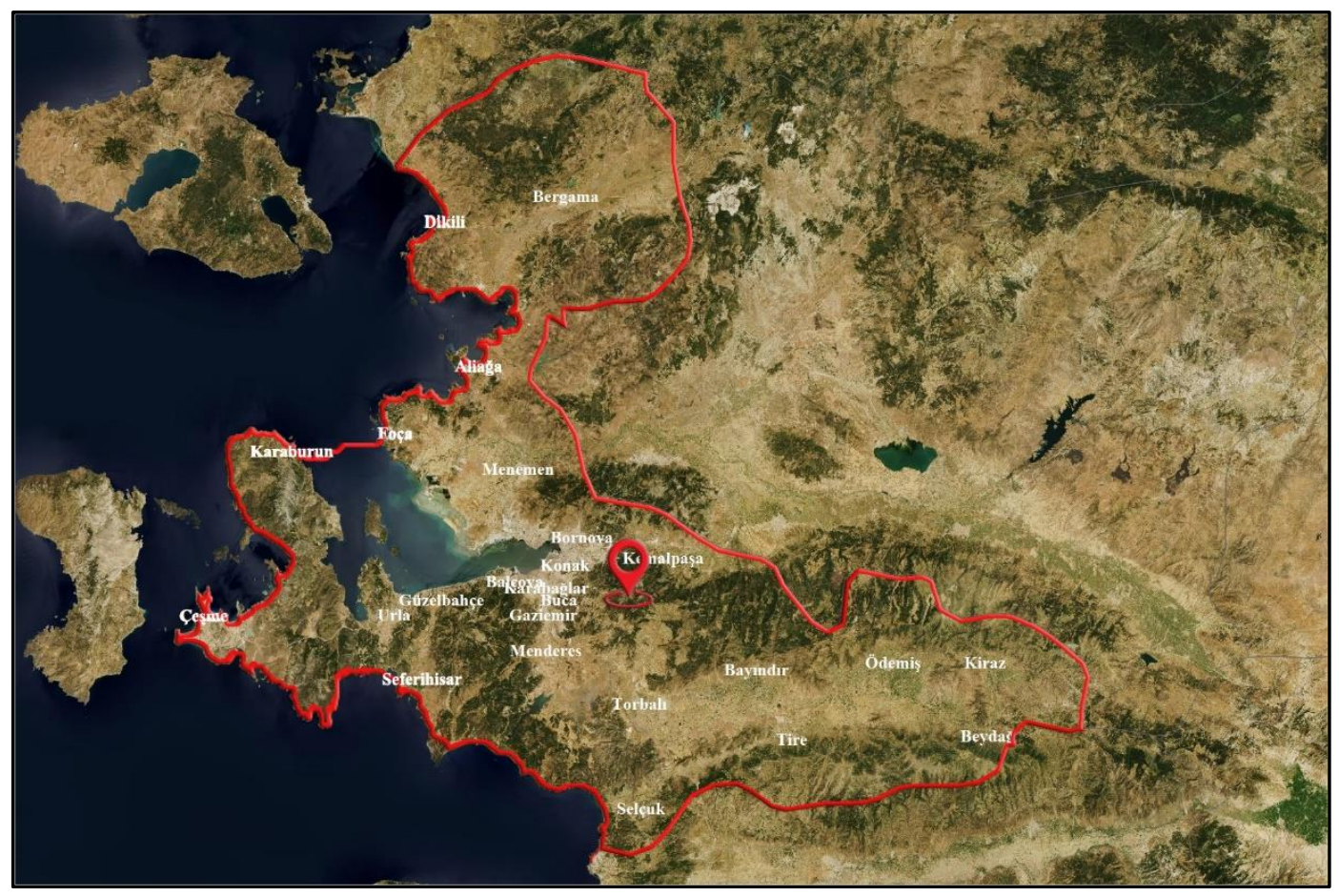

Figure 1- The location map of the study area

The distribution of the soil types are as follows: red-brown Mediterranean soils and limeless brown forest soils with the ratio of $16 \%$, alluvial and colluvial soils with the ratio of $12 \%$, brown forest soils with the ratio of $4 \%$, red Mediterranean soils, and rendzinas with the ratio of $3 \%$, chestnut soils with the ratio of $0.4 \%$ and regosols $\%$ with the ratio of $0.1 .22 .5 \%$ of the soils in İzmir are deep, or very deep, 4\% medium-deep, 38.5\% shallow, and 35\% very shallow (Dizdar 2003).

The properties of the collected soils for all depths are as follows: $\mathrm{pH}$ (KCL):7.2 $\mathrm{pH}$, organic matter: 7.3\%, total nitrogen: $975.0 \mathrm{~kg} / \mathrm{da}$, total phosphorus: $300.00 \mathrm{~kg} / \mathrm{da}$, total potassium $43.99 \mathrm{~kg} / \mathrm{da}$, clay: $9.1 \%$, cation exchange capacity: $347.1 \mathrm{mmol}+\mathrm{kg}$. The soil texture is sandy loam.

A part of the dataset used in the experiments was collected using IoT devices (Arduino Mega, Arduino Shield) and various sensors (DS18B20 soil temperature (ST) sensor and soil moisture (SM) sensor for measuring hourly data at the soil depths of 10, 20, 30, 40, and $50 \mathrm{~cm}$, and light-dependent resistor (LDR) sensor for hourly light intensity (LI)). The meteorological part of 
the dataset was obtained from the web page of weather.com that provides air temperature (AT), humidity (H), dew point (DP), air pressure (AP), wind speed (WS), wind direction (WD), and ultraviolet index (UV). Hourly values of the aforementioned features were taken into consideration. After data collection, the records with missing values were removed. Finally, 4500 instances were left for data analysis.

A sample fragment of the dataset at the depth of $50 \mathrm{~cm}$ between 01:00 and 04:00 p.m. on September 19, 2019, is given as hourly in Table 2. SM and LI sensors have raw analogue reading values of 0 to 1023 as shown in Table 2. If the value of SM is close to 1023, it means soil moisture is high, otherwise low. In the same manner, if the value of LI is high, the light intensity is a lot. For the prediction of ST of each depth, SM values from all depths are taken into consideration.

Table 2- A part of the dataset used in the experiments*

\begin{tabular}{|c|c|c|c|c|c|c|c|c|c|c|c|c|c|}
\hline $\begin{array}{l}A T \\
\left({ }^{\circ} \mathrm{C}\right) \\
\end{array}$ & $\begin{array}{c}H \\
(\%) \\
\end{array}$ & $\begin{array}{l}D P \\
\left({ }^{\circ} \mathrm{C}\right) \\
\end{array}$ & $\begin{array}{c}A P \\
(m b)\end{array}$ & $U V$ & $\begin{array}{c}W S \\
(\mathrm{~km} / \mathrm{s})\end{array}$ & $W D$ & $L I$ & SM50 & $S M_{40}$ & $S M_{30}$ & $S M_{20}$ & $S M_{10}$ & $\begin{array}{l}S T_{50} \\
\left({ }^{\circ} \mathrm{C}\right) \\
\end{array}$ \\
\hline 28 & 40 & 13 & 1015.2 & $7 / 10$ & 3 & Northwest & 900 & 322 & 335 & 268 & 270 & 282 & 22.56 \\
\hline 29 & 32 & 11 & 1013.9 & $7 / 10$ & 5 & Northwest & 874 & 316 & 337 & 267 & 267 & 279 & 23.00 \\
\hline 29 & 34 & 11 & 1014.2 & $5 / 10$ & 18 & West & 866 & 320 & 339 & 267 & 266 & 276 & 23.38 \\
\hline 28 & 28 & 13 & 1014.2 & $4 / 10$ & 23 & West & 843 & 317 & 339 & 275 & 264 & 272 & 23.82 \\
\hline
\end{tabular}

*AT, Air temperature; H, Humidity; DP, Dew point; AP, Air pressure; WS, Wind speed; WD, Wind direction; UV, Ultraviolet index; LI, Light intensity; SM, Soil moisture; ST, Soil temperature.

\subsection{Proposed method: Soil temperature prediction via self-training (STST)}

The rationale behind self-training is to increase the training set size with unlabeled data when there is a very small number of pre-labeled data compared to unlabeled ones so that a more optimized classifier model can be constructed using the updated labeled training set. Considering the problem of soil temperature prediction, we may not always be able to access all past data whose results are known to estimate new values. Because of the high cost of manual labeling, it is hard to obtain sufficient, reliable, and up-to-date labeled data for effective soil temperature prediction. In such cases, by applying the proposed Soil temperature prediction via self-training (STST) model, we first estimate the values for the unlabeled historical samples and then use all past records to estimate the new values for the future records.

The proposed approach (STST) has a number of advantages that can be summarized as follows:

- The traditional soil temperature prediction is limited to using only labeled data to build a regression model. Differently from the previous studies, the proposed STST approach overcomes this limitation and deals with the design of prediction models in the presence of both labeled and unlabeled data. In addition to labeled data, the STST approach also exploits unlabeled data to help improve soil temperature prediction performance. Due to the STST approach, the unlabeled data samples provide additional knowledge that is relevant for prediction, and they can successfully be used to improve the generalization ability of the learning system.

- An important advantage of the STST approach is that it can be used with the combination of any supervised base learner such as SVR, KNNReg, and ETReg. The STST approach is entirely unaware of the regression method, in fact, it simply learns from the labeled and pseudo-labeled samples as if they were regular labeled samples.

- $\quad$ Another advantage is that the STST approach can be applied to any soil data without any prior information about the given dataset. It does not make any specific knowledge and specific assumptions for the given data.

- Soil temperature prediction at different depths is useful in agricultural management (Abyaneh et al. 2016; Huang et al. 2020). However, the measured soil temperature data at various depths are rarely available for many locations. In many real-world agricultural applications, a huge amount of unlabeled data is available. The proposed STST approach addresses this inherent bottleneck by automatically allowing the model to integrate the available unlabeled data at various soil depths. Since the proposed STST approach covers multiple soil depths, it enables enormous agricultural applications, and so it expands the application of machine learning algorithms in the field of agriculture.

Figure 2 expresses the main course of this study as a series of processes. The first part is the collection of soil data at different depths, meteorological data, and light intensity by using IoT devices and sensors or by pulling data from web pages. After data collection, if needed, missing data imputation can also be performed, otherwise, the machine learning process including selftraining takes part. In the self-training phase, a machine learning model is firstly built with the initial labeled data for the purpose of classifying unlabeled instances, and then, it is re-trained by adding its own estimations to the labeled data. After that, future 
samples are assigned their predicted temperature values as an output. The final part is the reporting and presentation facility in order to adjust the findings in an interpretable format.

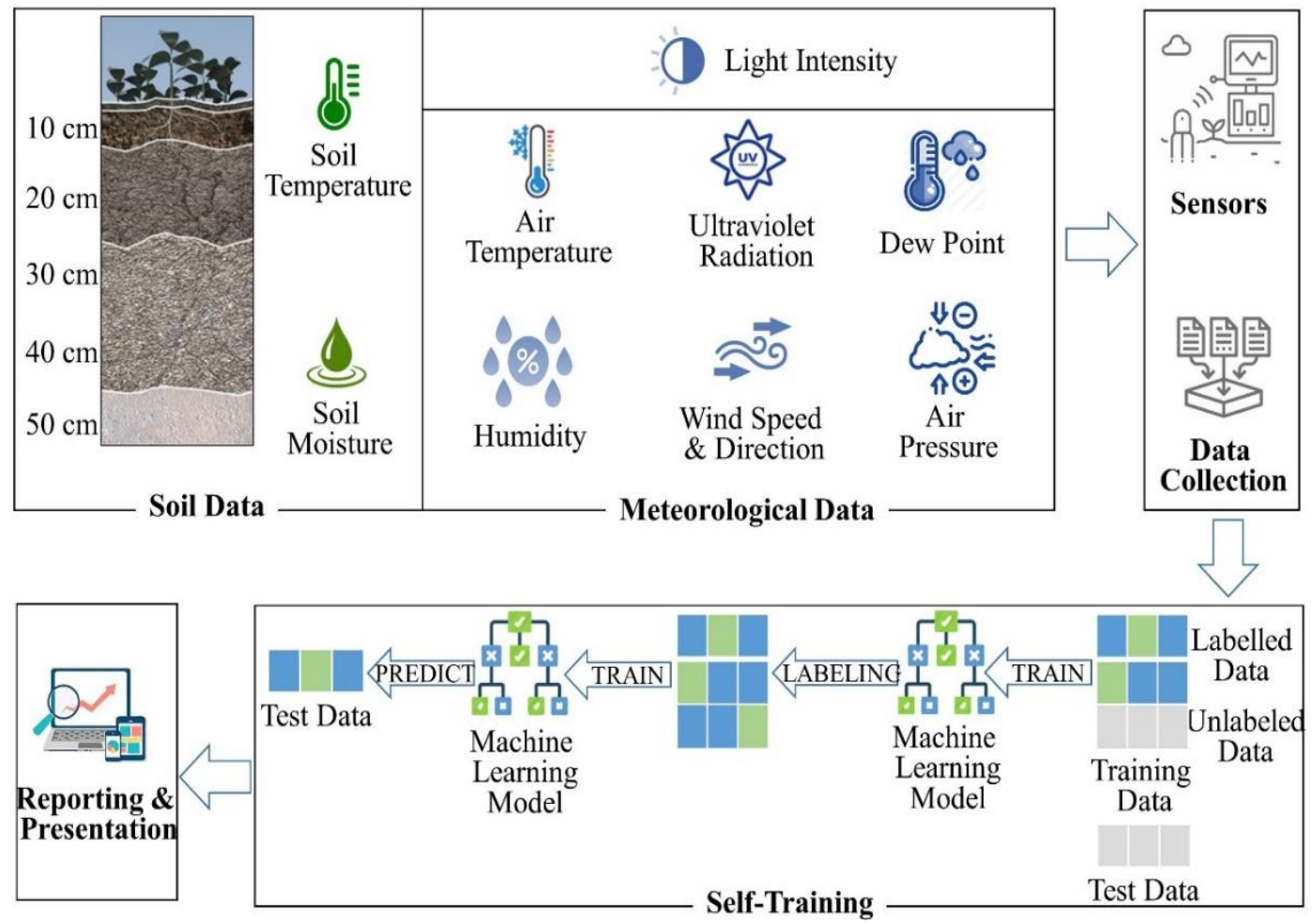

Figure 2- The general framework of the proposed "Soil temperature prediction via self-training (STST)" model

Algorithm 1 given below theoretically displays the pseudo-code of the training part of the proposed model. The aim is to obtain the soil temperature values $\left(Y^{*}\right)$ of new instances in $D_{\text {Test }}$ at all depths. In the first part, there are two sets of instances: the labeled dataset $\left(D_{L}\right)$ and the unlabeled dataset $\left(D_{U}\right)$. The hidden patterns affecting the soil temperature can be detected by analyzing the labeled instances. Therefore, using the instances in $D_{L_{d}}$, a classifier $C_{d}$ is trained and a model that facilitates labeling other instances is obtained at the depth $d$. In this way, the pseudo-label $\left(y_{i}\right)$ of each instance $x_{i}$ in $D_{U_{d}}$ is discovered. All the pseudo-labeled instances are then gathered together in $D_{d}$. Now, a new labeled training set $D_{\mathrm{ALL}}$ is ready by expanding the initially given $D_{L_{d}}$ with the pseudo-labeled set $D_{d}$. The final step is to predict the temperature values $\left(Y_{d}\right)$ of new instances at the depth $d$ by using the new classifier model $C_{d}$ trained with $D_{\mathrm{ALL}}$. The resulting output is the predicted soil temperature values of all depths as the collection of each $Y_{d}$ in the set $Y^{*}$. 
Algorithm 1. Soil temperature prediction via self-training (STST)
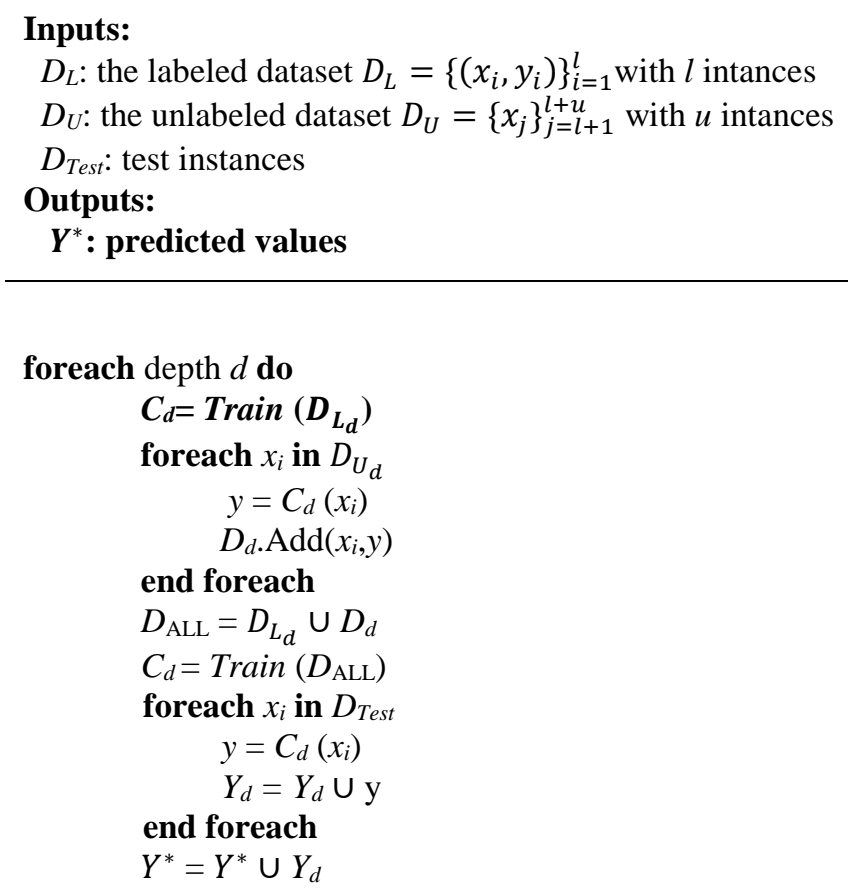

\section{End Algorithm}

\subsection{Machine learning methods}

The machine learning methods performed in the experiments are SVR, RF, KNNReg, ETReg, DTReg, and XGBoost. The parameters of all the applied methods were left as their default values in the sklearn library of Python.

\subsubsection{Support vector regression}

The main aim is to minimize the error by maximizing the margin around the separating hyperplane. The general formula can be written as an optimization problem as in Equation 1 where $w$ is the normal vector to the bounding planes, $C$ is the penalty associated with the instances which are either misclassified or violate the maximal margin, $\phi\left(X_{i}\right)$ is a function which maps data point $X_{i}$ into a higher dimensional space, $b$ shows the positions of bounding planes relative to the origin and $\xi$ is a slack variable for soft margins defined for linearly non-separable cases.

$$
\begin{aligned}
& \min \frac{1}{2}\|w\|^{2}+C \sum_{i=1}^{n} \xi_{i} \\
& \text { subject to } Y_{i}\left(w^{T} \phi\left(X_{i}\right)+b\right) \geq 1-\xi_{i}, \xi_{i} \geq 0
\end{aligned}
$$

In non-linear problems, the kernel functions, $K\left(X_{i}, X_{j}\right)=\phi\left(X_{i}\right)^{T} \phi\left(X_{j}\right)$, are used to transform the data into a higher dimensional feature space to make it possible to perform the linear separation. Two kernel functions are generally used for these cases as polynomial kernel (poly kernel) or Gaussian radial basis function (RBF kernel). For two samples $X_{i}$ and $X_{j}$, the poly kernel function and RBF kernel function can be written as in Equation 2 and Equation 3, respectively.

$$
\begin{aligned}
& K\left(X_{i}, X_{j}\right)=\left(a X_{i}^{T} X_{j}+b\right)^{d} \\
& K\left(X_{i}, X_{j}\right)=\exp \left(-\frac{\left\|X_{i}-X_{j}\right\|^{2}}{2 \sigma^{2}}\right)
\end{aligned}
$$

\subsubsection{K-nearest neighbors regression}

It is one of the instance-based lazy learners where the method memorizes the training dataset instead of learning a discriminative function for predicting future samples. It compares a given test instance with training instances that are similar to it. The parameter $k$ refers to the number of samples to be considered in the determination of the numeric outcome for a new sample. The 
nearest neighbors are calculated using one of the distance metrics such as Manhattan, Euclidean, Chebychev, Cosine, etc. In the experimental studies, Euclidean distance given in Equation 4, where two points are described as $X_{i}=\left(x_{i 1}, x_{i 2}, \ldots, x_{i m}\right)$ for $m$ features is used. The outcome of the $k$ nearest samples to a specific instance are averaged.

$$
\operatorname{Dist}\left(X_{1}, X_{2}\right)=\sqrt{\sum_{i=1}^{m}\left(x_{1 i}-x_{2 i}\right)^{2}}
$$

\subsubsection{Decision tree regression}

It is one of the supervised learning methods where the regression scenario is represented as a tree-based system in which each branch points out a possible outcome. The depth-first strategy in a top-down recursive and divide-and-conquer manner is applied to predict unknown target values for test cases. Each node of the tree refers to a specific attribute as the branches show their values. The leaves carry the results (the value of the class label).

The construction of a decision tree is started with a root node. The determination of the initial node is based on the mutual information which gives the highest benefit for learning. For this purpose, information gain given in Equation 5, which is calculated for each attribute, is used that $S$ is the instances of the parent node, $A$ is an attribute to perform the split, $S_{\text {Left }}$ and $S_{\text {Right }}$ are the samples found in the left and right child nodes, respectively, and $I$ is the impurity measure. Information gain evaluates the gain of each feature in the context of a target variable. It is performed by taking the mutual information (i.e. the determination of the statistical dependence) between two random variables. $I$ is the mean squared error (MSE) of the children nodes, which is given in Equation 8.

$$
\operatorname{InfoGain}(S, A)=I(S)-\left(\frac{\left|S_{\text {Left }}\right|}{|S|} I\left(S_{\text {Left }}\right)+\frac{\left|S_{\text {Right }}\right|}{|S|} I\left(S_{\text {Right }}\right)\right)
$$

\subsubsection{Random forest}

It is a meta estimator based on decision trees applied to many bootstrapped subsamples of a dataset. First of all, a specified number of decision tree regressors are built. A subset of features is randomly selected to be used as candidates at each split so that the constructed decision trees do not rely on the same set of features and high correlation among trees can be prevented. The bootstrapped instances also prevent the individual trees from overfitting. The numeric predictions of each estimator are averaged and assigned to the test sample as the final output. Equation 6 is used to make a prediction for a new sample $x$, where $B$ is the number of bootstrapping, $T_{i}$ is the bootstrapped tree constructed by a set of samples of size $n$, which is the total number of instances in the training data, and selecting $m$ variables from all features at random for iteration $i$. The best split point among $m$ variables is determined using the mean squared error as in Equation 8.

$$
\hat{f}_{B}(x)=\frac{1}{B} \sum_{i=1}^{B} T_{i}(x)
$$

\subsubsection{Extremely randomized trees}

It is an ensemble of decision trees where cut-points are randomly determined while splitting nodes, on the other hand, the whole samples are used as given at the beginning instead of performing bootstrapping. The final output is assigned by averaging the results of ensemble iterations. Two important parameters are the number of randomly selected features and the minimum sample size for splitting a node.

\subsubsection{Extreme gradient boosting}

XGBoost is also one of the ensemble models of decision trees. It is based on gradient boosting in which errors are minimized by the gradient descent algorithm. By adding models on top of each other iteratively, the errors of the previous model are corrected by the next predictor, until the training data is accurately predicted or reproduced by the model. Instead of assigning different weights to the classifiers after every iteration, gradient boosting fits the new model to new residuals of the previous prediction and then minimizes the loss when adding the latest prediction. XGBoost uses this algorithm with an additional custom regularization term in the objective function. XGBoost uses a loss function to build trees by minimizing the value in Equation 7, where the first part represents the loss function calculating the pseudo residuals of the predicted $\left(\widehat{y}_{l}\right)$ and the real value $\left(y_{i}\right)$ of the $i^{\text {th }}$ instance in each leaf, the second part includes $T$ as the number of leaves, $\gamma$ as the penalty parameter used for pruning, $\lambda$ as a regularization term, and $w$ as the leaf weights.

$$
\begin{aligned}
& \mathcal{L}(\phi)=\sum_{i} \ell\left(\widehat{y}_{l}, y_{i}\right)+\sum_{k} \Omega\left(f_{k}\right) \\
& \text { where } \Omega\left(f_{k}\right)=\gamma T+\frac{1}{2} \lambda\|w\|^{2}
\end{aligned}
$$




\section{Results and Discussion}

From here onwards, the abbreviation of the self-training (ST) method followed by the abbreviation of the base classifier technique is used to refer to the related approach. For example, ST-SVR refers to the self-training method with the SVR base classifier.

Three performance metrics (mean squared error (MSE) given in Equation 8, coefficient of determination $\left(\mathrm{R}^{2}\right)$ given in Equation 9, and mean absolute percentage error (MAPE) given in Equation 10, where ST is the measured value of soil temperature, $\widetilde{S T}$ is the predicted value of soil temperature, $\overline{S T}$ is the mean of the observed data, and $n$ is the number of samples) were calculated to evaluate the usability of the proposed methodology and to select the best one in terms of the given criteria. The results show the outputs of ten-fold cross-validation. By considering the ratio of initially given training data as $p \%$, the experimental results were obtained for all varying values of $p$ as $5 \%$ to $85 \%$ with an increment of 5 .

$$
\begin{aligned}
& \mathrm{MSE}=\frac{1}{n} \sum_{i=1}^{n}\left(S T_{i}-\widetilde{S T_{l}}\right)^{2} \\
& \mathrm{R}^{2}=1-\frac{\sum_{i=1}^{n}\left(S T_{i}-\widetilde{S T_{l}}\right)^{2}}{\sum_{i=1}^{n}\left(S T_{i}-\overline{S T_{l}}\right)^{2}} \\
& \mathrm{MAPE}=\frac{1}{n} \sum_{i=1}^{n}\left|\frac{S T_{i}-\widetilde{S T_{l}}}{S T_{i}}\right| * 100
\end{aligned}
$$

Table 3 displays the MSE values of the methods under the self-training framework at the depth of $50 \mathrm{~cm}$. Even though there are very few known cases of soil temperature, in the beginning, the constructed models achieved a remarkable performance by predicting too close to the real values for test cases. The self-training model led to increasing the amount of labeled data by pseudo-labeling the past training data by applying one of the regression methods described in Section 2.3. As a result, the constructed regression model had the advantage of discovering more patterns hidden in data due to more sets of instances with known outputs.

Table 3- The comparison of the applied methods under self-training framework in terms of MSE values

\begin{tabular}{lllllll}
\hline & & \multicolumn{5}{c}{ Methods } \\
$\%$ & ST-RF & ST-SVR & ST-KNNReg & ST-ETReg & ST-XGBoost & ST-DTReg \\
\hline 5 & 2.293 & 18.594 & 6.374 & 5.128 & $\mathbf{2 . 1 8 9}$ & 4.573 \\
10 & 1.466 & 16.584 & 4.020 & 3.444 & $\mathbf{1 . 2 7 9}$ & 3.041 \\
15 & 1.256 & 15.459 & 3.134 & 3.070 & $\mathbf{1 . 0 0 7}$ & 2.448 \\
20 & 1.197 & 14.537 & 2.779 & 2.607 & $\mathbf{0 . 9 3 4}$ & 2.234 \\
25 & 1.035 & 14.065 & 2.411 & 2.457 & $\mathbf{0 . 7 7 2}$ & 2.052 \\
30 & 0.891 & 13.553 & 2.331 & 2.189 & $\mathbf{0 . 7 3 6}$ & 1.702 \\
35 & 0.816 & 13.195 & 2.068 & 2.140 & $\mathbf{0 . 6 3 8}$ & 1.425 \\
40 & 0.747 & 12.920 & 1.991 & 2.047 & $\mathbf{0 . 5 8 2}$ & 1.402 \\
45 & 0.728 & 12.554 & 1.921 & 1.868 & $\mathbf{0 . 5 5 2}$ & 1.530 \\
50 & 0.670 & 12.259 & 1.728 & 1.687 & $\mathbf{0 . 5 2 2}$ & 1.219 \\
55 & 0.611 & 12.004 & 1.732 & 1.626 & $\mathbf{0 . 5 0 6}$ & 1.203 \\
60 & 0.567 & 11.730 & 1.672 & 1.593 & $\mathbf{0 . 4 8 2}$ & 1.197 \\
65 & 0.539 & 11.557 & 1.617 & 1.452 & $\mathbf{0 . 4 8 1}$ & 1.118 \\
70 & 0.490 & 11.310 & 1.559 & 1.255 & $\mathbf{0 . 4 1 9}$ & 0.960 \\
75 & 0.508 & 11.113 & 1.546 & 1.226 & $\mathbf{0 . 4 3 2}$ & 1.008 \\
80 & 0.467 & 10.889 & 1.489 & 1.160 & $\mathbf{0 . 3 8 6}$ & 1.019 \\
85 & 0.443 & 10.721 & 1.457 & 1.268 & $\mathbf{0 . 3 8 5}$ & 1.005 \\
\hline
\end{tabular}

Furthermore, the most noticeable thing is the reduction in error values as the percentage ( $p$ ) value increases. It is because as the number of training instances real labels of which are known rises, the pseudo-labeled training data is less required to predict the outcome of new cases. More accurate estimations can be obtained as a result.

The best results for all the ratio values were achieved when ST-XGBoost was performed. XGBoost is one of the ensemble learning methods which boosts high performance compared to single learners so it was expected that its results were good. ST$\mathrm{RF}$ is another ensemble learning method that followed ST-XGBoost in terms of low error values. The highest errors were obtained when ST-SVR was the learner. It can be inferred that ST-SVR required more labeled training data in order to find the 
optimal hyperplane to make more accurate predictions. It could not manage to perform well when the value of $p$ is small. The performance of ST-SVR may be improved by changing the kernel type or updating the parameters instead of using default values.

Table 4 shows the MAPE values of the applied methods at the depth of $50 \mathrm{~cm}$. As in Table 3, there is a tendency to decrease in the error values when the percentage of the initially given labeled training data is increased. ST-XGBoost performs the best $(7.436 \%-3.456 \%)$ especially for the $\mathrm{p}$ values between $5 \%$ and $60 \%$. In addition to ST-XGBoost, ST-RF also achieves the predictions with the least errors $(3.434 \%-3.059 \%)$ for the p values of $65 \%$ to $85 \%$. ST-DTReg is the leading one among the single learners with error rates of $9.706 \%-4.001 \%$.

Table 4- The comparison of the applied methods under self-training framework in terms of MAPE values (\%)

\begin{tabular}{|c|c|c|c|c|c|c|}
\hline \multirow[b]{2}{*}{$\%$} & \multirow[b]{2}{*}{$S T-R F$} & \multirow[b]{2}{*}{$S T-S V R$} & \multicolumn{3}{|c|}{ Methods } & \multirow[b]{2}{*}{ ST-DTReg } \\
\hline & & & ST-KNNReg & ST-ETReg & ST-XGBoost & \\
\hline 5 & 7.544 & 26.706 & 13.921 & 10.899 & 7.436 & 9.706 \\
\hline 10 & 6.157 & 24.932 & 11.410 & 8.933 & 5.939 & 8.115 \\
\hline 15 & 5.522 & 24.107 & 9.821 & 8.110 & 5.334 & 7.120 \\
\hline 20 & 5.125 & 23.025 & 9.247 & 7.549 & 4.819 & 6.712 \\
\hline 25 & 4.746 & 22.592 & 8.440 & 7.226 & 4.395 & 6.134 \\
\hline 30 & 4.493 & 22.141 & 8.328 & 6.827 & 4.223 & 5.948 \\
\hline 35 & 4.267 & 21.688 & 7.621 & 6.555 & 4.082 & 5.445 \\
\hline 40 & 4.191 & 21.405 & 7.456 & 6.309 & 3.914 & 5.437 \\
\hline 45 & 3.990 & 20.906 & 7.156 & 5.973 & 3.722 & 5.177 \\
\hline 50 & 3.828 & 20.641 & 6.843 & 5.827 & 3.572 & 4.812 \\
\hline 55 & 3.717 & 20.229 & 6.820 & 5.741 & 3.581 & 4.843 \\
\hline 60 & 3.547 & 20.053 & 6.720 & 5.432 & 3.456 & 4.622 \\
\hline 65 & 3.434 & 19.842 & 6.468 & 5.188 & 3.486 & 4.352 \\
\hline 70 & 3.288 & 19.554 & 4.338 & 4.974 & 3.275 & 4.275 \\
\hline 75 & 3.258 & 19.295 & 6.266 & 4.759 & 3.271 & 4.243 \\
\hline 80 & 3.126 & 19.095 & 6.194 & 4.657 & 3.156 & 4.129 \\
\hline 85 & 3.059 & 18.890 & 6.077 & 4.665 & 3.109 & 4.001 \\
\hline
\end{tabular}

The comparisons of the methods according to $\mathrm{R}^{2}$ values are indicated in Figure 3 at the depth of $50 \mathrm{~cm}$. $\mathrm{R}^{2}$ expresses the proportion of the variance for a dependent variable that is explained by the model's inputs. In this study, it is the relationship between soil temperature and other independent variables such as soil moisture, air temperature, ultraviolet radiation, etc. as in the work of Shamshirband et al. (2020) and Tabari et al. (2011). According to the results, the general impression is that there is a steady increase as the value of $p$ increases. The same condition as in MSE is valid for $\mathrm{R}^{2}$ that ST-SVR has the lowest coefficient of determination (0.331 to 0.614$)$ while the best results are found in ST-XGBoost (0.921 to 0.987). Similarly, at the more sensitive depth of $10 \mathrm{~cm}$, the best prediction accuracy was achieved by the ST-XGBoost algorithm. The best learner, ST-XGBoost, has the $\mathrm{R}^{2}$ values in the interval of 0.927 to 0.986 , while the values of the ST-SVR method is in the interval of 0.321 to 0.606. 


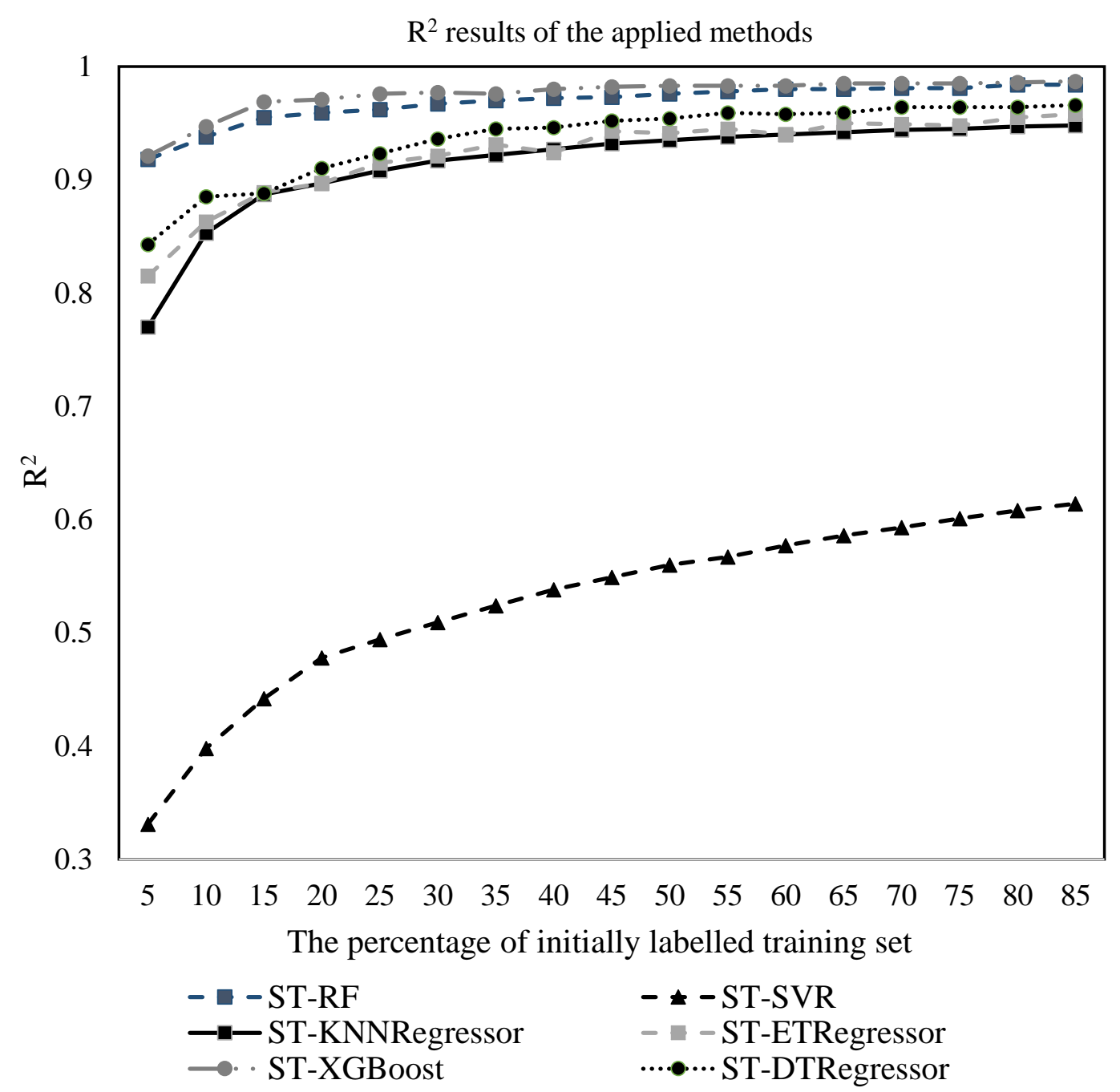

Figure 3- The comparison of the applied methods under self-training framework in terms of $R^{2}$ values (ST-RF: the RF method combined with self-training, ST-SVR: the SVR method combined with self-training, ST-KNNRegressor: the KNNRegressor method combined with self-training, ST-ETRegressor: the ETRegressor method combined with selftraining, ST-XGBoost: the XGBoost method combined with self-training, ST-DTRegressor: the DTRegressor method combined with self-training)

Figure 4 displays the best-performed model, ST-XGBoost, in terms of the values of MSE at all depths. It is apparent that the model predicts soil temperature well at the depth of $50 \mathrm{~cm}$ while the values at the depth of $30 \mathrm{~cm}$ are generally estimated worse compared to others. Besides, as in Table 3, MSE values at depths of 10, 20, 30, and $40 \mathrm{~cm}$ are decreased when the size of the labeled training set is increased. 


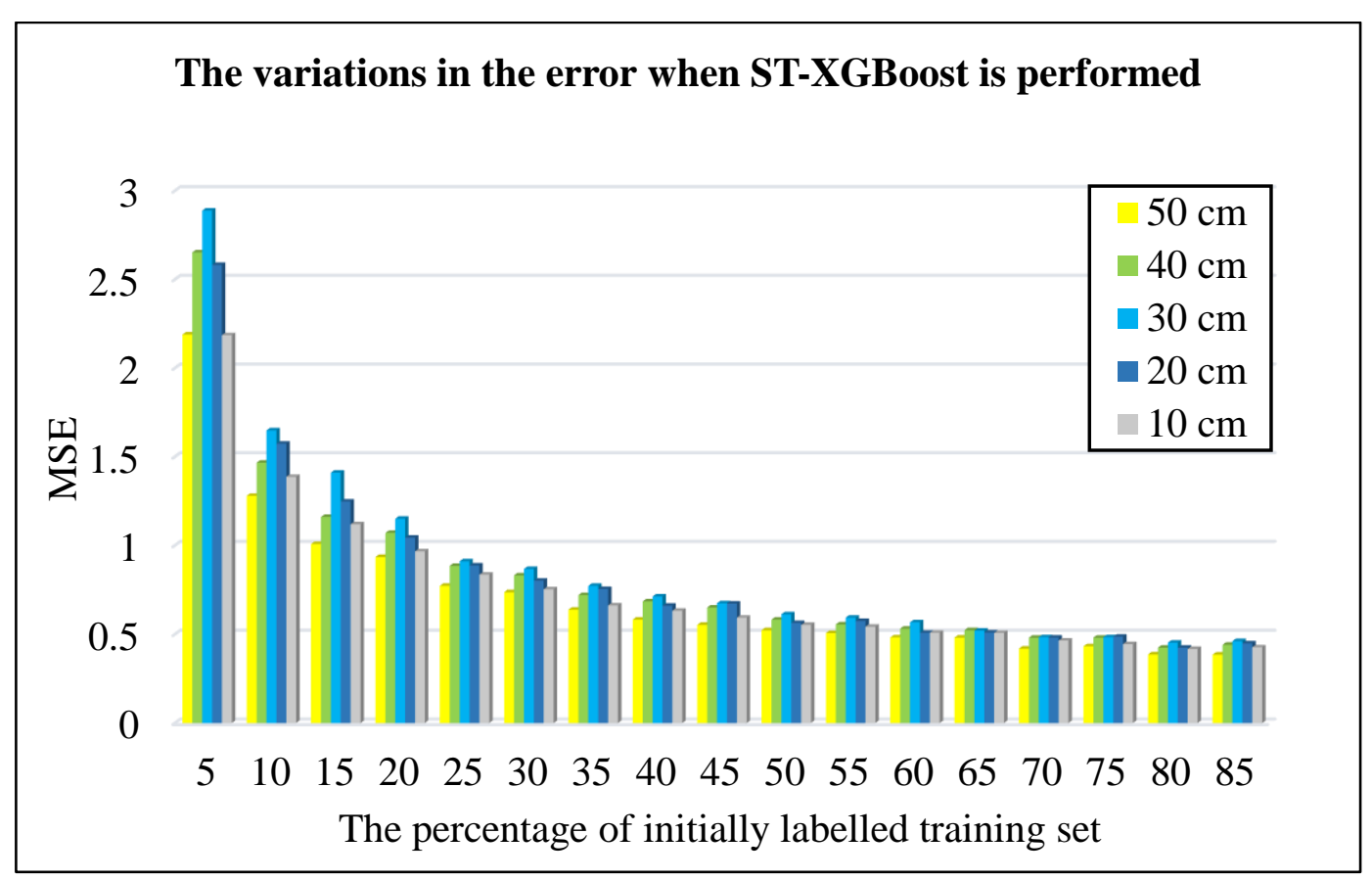

Figure 4- The results of MSE when the best predictor (ST-XGBoost) was performed at all soil depths

Figure 5 demonstrates the predicted and the measured values of test samples of 10 -fold cross-validation steps separately when ST-XGBoost is performed at the depth of $50 \mathrm{~cm}$ and $\mathrm{p}$ is $85 \%$ of the whole data. In each iteration, whole data including 4500 samples are divided into training and test $(90 \%$ of data as the training set and $10 \%$ of data as the test set) and this procedure is repeated ten times. In that way, the selection of the samples with different characteristics are increased instead of experimenting only with predefined test cases. The advantage of this is that, perhaps, the samples that are easy to predict in one iteration are collected in the test set, while in another iteration, the opposite (difficult samples for prediction) can be observed. Since the common result of all of them is obtained, a better inference is made than depending on a result of a single sample set. In this direction, Figure 5 shows clearly that the ST-XGBoost model obtains soil temperature values that are very close to the real measurements in each fold. 

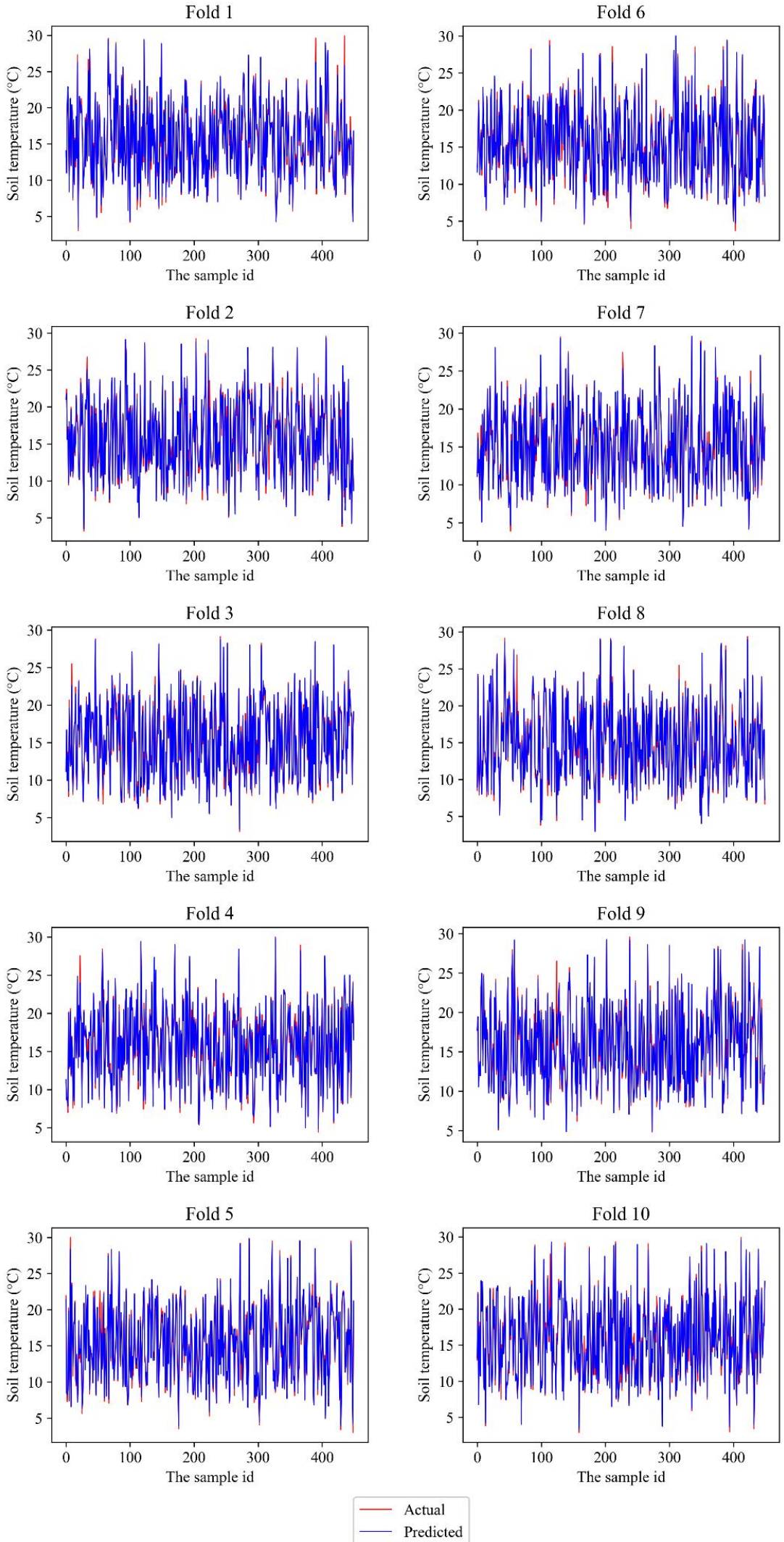

Figure 5- The predicted and the real values of the soil temperature when the ST-XGBoost model was applied at the depth of $50 \mathrm{~cm}$ and $p$ is $85 \%$

In order to show the trend in the results as the soil depth changes, Table 5 demonstrates the MSE values of each applied method by taking their average for all $p$ values from 5 to 85 . Especially for ensemble learning methods, there is a general pattern that the error first increases for the soil depth of 10 to 30 and then a decreasing trend follows as the depth increases from 40 to $50 \mathrm{~cm}$. Their common characteristic is that they can better estimate the deepest soil temperature. On the contrary, there is a decreasing trend in most of the cases for single learners from shallow to deeper parts. ST-SVR and ST-DTReg manage to predict the best at the depth of $50 \mathrm{~cm}$ while ST-KNNReg performs well at the depth of $40 \mathrm{~cm}$. The main inference for the proposed 
model is that the more accuracy is generally obtained the deeper the soil. It is clear that the effect of the meteorological parameters on the soil temperature is greater in the regions close to the soil surface. While the soil in the shallow regions is affected more by external factors such as rainfall and wind, as the soil depth increases, a more stable environment is found in terms of the soil temperature modelling, and regression models, therefore, create better predictive models with less error.

Table 5- The comparison of the mean values of the applied methods in terms of MSE values under self-training framework at different soil depths

\begin{tabular}{lrrrrr}
\hline \multirow{2}{*}{ Methods } & 50 & 40 & 30 & 20 & 10 \\
\hline ST-RF & 0.866 & 0.927 & 0.958 & 0.941 & 0.931 \\
ST-ETReg & 2.130 & 2.339 & 2.492 & 2.502 & 2.321 \\
ST-SVR & 13.120 & 13.986 & 14.412 & 14.311 & 14.384 \\
ST-XGBoost & 0.724 & 0.831 & 0.894 & 0.836 & 0.764 \\
ST-KNNReg & 2.343 & 2.286 & 2.288 & 2.328 & 2.637 \\
ST-DTReg & 1.714 & 1.848 & 1.957 & 1.941 & 1.920 \\
\hline
\end{tabular}

Table 6 shows the $\mathrm{R}^{2}$ results at different soil depths to compare our study with the recent studies in the literature. The values are the best $\mathrm{R}^{2}$ values obtained with the best parameter combinations in the mentioned studies and our results obtained on our dataset are the optimal $\mathrm{R}^{2}$ values of the best method, ST-XGBoost, at the specified depths. It is apparent that our proposed method generally outperforms the other models and it manages to estimate soil temperature accurately.

Table 6- The accuracy of the results $\left(\mathbf{R}^{2}\right)$ obtained in this study and the similar results obtained in the literature

\begin{tabular}{|c|c|c|c|c|}
\hline \multirow[b]{2}{*}{ Ref } & \multirow[b]{2}{*}{ Algorithm } & \multirow[b]{2}{*}{$\begin{array}{l}\text { Depth } \\
(\mathrm{cm})\end{array}$} & \multicolumn{2}{|c|}{$\overline{R^{2}}$} \\
\hline & & & $\begin{array}{l}\text { Existing } \\
\text { Method }\end{array}$ & $\begin{array}{l}\text { Proposed } \\
\text { Method } \\
\text { (STST) }\end{array}$ \\
\hline Alizamir et al. 2020a & $\begin{array}{ll}\text { - } & \text { Deep Echo State Network (Deep ESN) } \\
\text { - } & \text { Multilayer Perceptron Neural Network (MLPNN) } \\
\text { - } & \text { M5Prime Tree } \\
\text { - } & \text { Random Forest } \\
\end{array}$ & $\begin{array}{l}20 \\
10 \\
10 \\
10 \\
\end{array}$ & $\begin{array}{l}0.970 \\
0.890 \\
0.870 \\
0.900 \\
\end{array}$ & $\begin{array}{l}0.985 \\
0.986 \\
0.986 \\
0.986\end{array}$ \\
\hline Li et al. 2020 & $\begin{array}{ll}\text { - } & \text { Integrated Bidirectional Long Short-Term Memory } \\
\text { - } & \text { Network (BiLSTM) } \\
\text { - } & \text { Bidirectional Long Short-Term Memory Network } \\
& \text { (BiLSTM) } \\
\text { - } & \text { Deep Neural Network (DNN) } \\
\text { - } & \text { Random Forest (RF) } \\
\text { - } & \text { Support Vector Regression (SVR) } \\
\text { - } & \text { Linear Regression (LR) } \\
\end{array}$ & 50 & $\begin{array}{l}0.920 \\
0.880 \\
0.860 \\
0.870 \\
0.860 \\
0.790 \\
0.420\end{array}$ & 0.986 \\
\hline Penghui et al. 2020 & $\begin{array}{ll}\text { - } & \text { Adaptive Neuro-Fuzzy Inference System with } \\
& \text { Grasshopper Optimization Algorithm (ANFIS-mSG) }\end{array}$ & 10 & 0.977 & 0.986 \\
\hline Guan et al. 2020 & $\begin{array}{l}\text { - The Hybrid of Multilayer Perceptron by Invasive Weed } \\
\text { Optimization (MLP-IWO) }\end{array}$ & 20 & 0.962 & 0.985 \\
\hline Alizamir et al. 2020b & $\begin{array}{ll} & \text { Extreme Learning Machine (ELM) } \\
\text { - } & \text { Artificial Neural Networks (ANN) } \\
\text { - } & \text { Classification and Regression Trees (CART) } \\
\text { - } & \text { Group Method of Data Handling (GMDH) } \\
\text { - } & \text { Multi-Linear Regression (MLR) } \\
\end{array}$ & $\begin{array}{l}10 \\
50 \\
10 \\
10 \\
50\end{array}$ & $\begin{array}{l}\mathbf{0 . 9 8 6} \\
0.984 \\
0.984 \\
\mathbf{0 . 9 8 8} \\
\mathbf{0 . 9 8 8} \\
\end{array}$ & $\begin{array}{l}\mathbf{0 . 9 8 6} \\
\mathbf{0 . 9 8 6} \\
\mathbf{0 . 9 8 6} \\
0.986 \\
0.986 \\
\end{array}$ \\
\hline Huang et al. 2020 & - Multivariate Linear Regression & $\begin{array}{l}10 \\
20 \\
40 \\
\end{array}$ & $\begin{array}{l}0.915 \\
0.889 \\
0.799 \\
\end{array}$ & $\begin{array}{l}0.986 \\
0.985 \\
0.986 \\
\end{array}$ \\
\hline Behmanesh \& Mehdizadeh 2017 & $\begin{array}{ll}\text { - } & \text { Gene Expression Programming (GEP) } \\
\text { - } & \text { Artificial neural networks (ANN) } \\
\text { - } & \text { Multiple linear regression (MLR) } \\
\end{array}$ & 10 & $\begin{array}{l}0.974 \\
0.980 \\
0.971 \\
\end{array}$ & 0.986 \\
\hline Abyaneh et al. 2016 & - Artificial Neural Networks (ANN) & $\begin{array}{l}10 \\
20 \\
30 \\
50 \\
\end{array}$ & $\begin{array}{l}0.968 \\
0.926 \\
0.893 \\
0.872 \\
\end{array}$ & $\begin{array}{l}0.986 \\
0.985 \\
0.985 \\
0.986 \\
\end{array}$ \\
\hline Ozturk et al. 2011 & - Artificial Neural Networks (ANN) & $\begin{array}{l}10 \\
20 \\
50\end{array}$ & $\begin{array}{l}0.960 \\
0.981 \\
0.966\end{array}$ & $\begin{array}{l}0.986 \\
0.985 \\
0.986\end{array}$ \\
\hline
\end{tabular}


The main findings of the study can be concluded as follows: 1) It was observed that "self-training" smartly provides many advantages for predicting soil temperature, including reducing cost and providing additional information present in unlabeled data. 2) The proposed STST approach has the potential to expand the application of machine learning in the agriculture sector, thanks to its advantages. 3) The ST-XGBoost method outperformed the other methods (ST-RF, ST-ETReg, ST-SVR, STKNNReg, and ST-DTReg) in terms of prediction accuracy. 4) The prediction error changes according to the soil depth. 5) The accuracy of soil temperature prediction increased as the number of labeled data samples increased.

\section{Conclusions}

In this study, soil temperature at various soil depths was predicted using the proposed model, Soil Temperature prediction via Self-Training (STST). The past soil temperature \& soil moisture data and meteorological data of Izmir, Turkey were considered in the interval of 01.09.2019 and 22.05.2020. The experimental results showed that self-training empowered the regression methods by presenting a more labeled pool of data for training a model for prediction. In this way, test samples were estimated more accurately using the information hidden in the expanded labeled instances instead of using few samples with known past values. Especially ensemble learning methods (ST-XGBoost and ST-RF) managed to capture the dynamics better behind the soil temperature prediction compared to other ones under the self-training framework. The best model, ST-XGBoost respectively obtained the results in the range of $0.385-2.888,3.109 \%-8.740 \%$, and $0.905-0.986$ at depths of 5, 10, 20, 30, 40, and 50 cm for the performance metrics MSE, MAPE, and $\mathrm{R}^{2}$. In addition, the best predictions were generally made at the depth of $50 \mathrm{~cm}$ with the mean MSE values of 0.866, 2.130, 13.120, 1.724, and 1.714 for ST-RF, ST-ETReg, ST-SVR, ST-XGBoost, and ST-DTReg, respectively.

This study contributes to the agricultural field in a way that plant growth can be handled more efficiently by taking the predicted soil temperature values into account. An automated irrigation system or cooling/heating system can be set up according to the variation in the temperature of the predicted time intervals. In the same manner, as future work, the proposed model may be customized and updated in order to estimate the soil moisture, which is another important parameter in plant production.

\section{References}

Abyaneh H Z, Varkeshi M B, Golmohammadi G \& Mohammadi K (2016). Soil temperature estimation using an artificial neural network and co-active neuro-fuzzy inference system in two different climates. Arabian Journal of Geosciences 9(5): 377. https://10.1007/s12517-0162388-8

Akengin H \& Dölek İ (2019). Physical Geography of Turkey. Pegem Akademi, Ankara (In Turkish)

Alizamir M, Kim S, Zounemat-Kermani M, Heddam S, Shahrabadi A H \& Gharabaghi B (2020a). Modelling daily soil temperature by hydrometeorological data at different depths using a novel data-intelligence model: deep echo state network model. Artificial Intelligence Review 54: 2863-2890. https://doi.org/10.1007/s10462-020-09915-5

Alizamir M, Kisi O, Ahmed A N, Mert C, Fai C M, Kim S, Kim N W \& El-Shafie A (2020b). Advanced machine learning model for better prediction accuracy of soil temperature at different depths. Plos One 15(4): e0231055. https://doi.org/10.1371/journal.pone.0231055

Anton C A, Matei O \& Avram A (2019). Collaborative data mining in agriculture for prediction of soil moisture and temperature. In: Computer Science On-line Conference (CSOC 2019), 24-27 April, Zlin, Czech Republic pp. 141-151. https://doi.org/10.1007/978-3-030-19807-7_15

Behmanesh J \& Mehdizadeh S (2017). Estimation of soil temperature using gene expression programming and artificial neural networks in a semiarid region. Environmental Earth Sciences 76(2): 76. https://doi.org/10.1007/s12665-017-6395-1

Belkin M, Niyogi P \& Sindhwani V (2006). Manifold regularization: A geometric framework for learning from labeled and unlabeled examples. Journal of Machine Learning Research 7(Nov): 2399-2434

Bilgili M (2010). Prediction of soil temperature using regression and artificial neural network models. Meteorology and Atmospheric Physics 110(1-2): 59-70. https://doi.org/10.1007/s00703-010-0104-x

Bilgili M (2011). The use of artificial neural networks for forecasting the monthly mean soil temperatures in Adana, Turkey. Turkish Journal of Agriculture and Forestry 35(1): 83-93. https://10.3906/tar-1001-593

Bilgili M (2012). Regional assessment of monthly soil temperatures in the Aegean Region of Turkey. Arabian Journal for Science and Engineering 37(3): 765-775. https://doi.org/10.1007/s13369-012-0199-0

Bilgili M, Sahin B \& Sangun L (2013). Estimating soil temperature using neighboring station data via multi-nonlinear regression and artificial neural network models. Environmental Monitoring and Assessment 185(1): 347-358. https://doi.org/10.1007/s10661-012-2557-5

Bolca M, Kurucu Y, Dengiz O \& Nahry A D H (2011). Terrain characterization for soils survey of Kucuk Menderes plain, South of Izmir, Turkey, using remote sensing and GIS techniques. Zemdirbyste-Agriculture 98: 93-104

Citakoglu H (2017). Comparison of artificial intelligence techniques for prediction of soil temperatures in Turkey. Theoretical and Applied Climatology 130(1-2): 545-556. https://doi.org/10.1007/s00704-016-1914-7

Dadashzadeh M, Abbaspour-Gilandeh Y, Mesri-Gundoshmian T, Sabzi S, Hernández-Hernández J L, Hernández-Hernández M \& Arribas J I (2020). Weed classification for site-specific weed management using an automated stereo computer-vision machine-learning system in rice fields. Plants 9(5): 559. https://doi.org/10.3390/plants9050559

Dizdar M Y (2003). Turkey's land resources. Retrieved in January, 10, 2021 from https://www.zmo.org.tr/ (In Turkish)

Friedl M A (2018). Remote sensing of croplands. Comprehensive Remote Sensing 6: 78-95. https://doi.org/10.1016/B978-0-12-4095489.10379-3

Giraddi S, Desai S \& Deshpande A (2020). Deep Learning for Agricultural Plant Disease Detection. In: Proceedings of the 1st International Conference on Data Science, Machine Learning and Applications (ICDSMLA 2019), 21-22 Nov, Pune, India, pp. 864-871. https://doi.org/10.1007/978-981-15-1420-3_93

Gönençgil B, Biricik A S, Atalay İ, Aydınözü D, Çoban A \& Ertek A (2016). Turkey physical geography. Retrieved in October, 9 , 2021 from http://auzefkitap.istanbul.edu.tr/ (In Turkish) 
Guan Y, Shen Y, Mohammadi B \& Sadat M A (2020). Estimation of soil temperature based on meteorological parameters by the HYBR ID INVASIVE Weed Optimization Algorithm Model. IOP Conference Series: Earth and Environmental Science 428: 012059. https://10.1088/1755-1315/428/1/012059

Hamrani A, Akbarzadeh A \& Madramootoo C A (2020). Machine learning for predicting greenhouse gas emissions from agricultural soils. Science of the Total Environment 741: 140338. https://doi.org/10.1016/j.scitotenv.2020.140338

Hillel D (2005). Thermal properties and processes. In: D Hillel (Ed.), Encyclopedia of Soils in the Environment, Academic Press, pp. 156-163

Huang R, Huang J X, Zhang C, Ma H Y, Zhuo W, Chen Y Y, Zhu D H, Wu Q \& Mansaray L R (2020). Soil temperature estimation at different depths, using remotely-sensed data. Journal of Integrative Agriculture 19(1): 277-290. https://doi.org/10.1016/S2095-3119(19)62657-2

Kapur S, Aydın M, Akça E \& Reich P (2018). Climate change and soils. In: S Kapur, E Akça \& H Günal (Eds.), The Soils of Turkey, Springer, pp. 45-55. https://doi.org/10.1007/978-3-319-64392-2_4

Kisi O, Tombul M \& Kermani M Z (2015). Modeling soil temperatures at different depths by using three different neural computing techniques. Theoretical and Applied Climatology 121(1-2): 377-387. https://doi.org/10.1007/s00704-014-1232-x

Kisi O, Sanikhani H \& Cobaner M (2017). Soil temperature modeling at different depths using neuro-fuzzy, neural network, and genetic programming techniques. Theoretical and Applied Climatology 129(3-4): 833-848. https://doi.org/10.1007/s00704-016-1810-1

Nandy A \& Singh P K (2020). Farm efficiency estimation using a hybrid approach of machine-learning and data envelopment analysis: evidence from rural eastern India. Journal of Cleaner Production 267: 122106. https://doi.org/10.1016/j.jclepro.2020.122106

Niedbała G, Kurasiak-Popowska D, Stuper-Szablewska K \& Nawracała J (2020). Application of artificial neural networks to analyze the concentration of ferulic acid, deoxynivalenol, and nivalenol in winter wheat grain. Agriculture 10(4): 127. https://doi.org/10.3390/agriculture10040127

Ozturk M, Salman O \& Koc M (2011). Artificial neural network model for estimating the soil temperature. Canadian Journal of Soil Science 91(4): 551-562. https://doi.org/10.4141/cjss10073

Pekel E (2020). Estimation of soil moisture using decision tree regression. Theoretical and Applied Climatology 139(3): 1111-1119. https://doi.org/10.1007/s00704-019-03048-8

Penghui L, Ewees A A, Beyaztas B H, Qi C, Salih S Q, Al-Ansari N, Bhagat S K, Yaseen Z M \& Singh V P (2020). Metaheuristic optimization algorithms hybridized with artificial intelligence model for soil temperature prediction: Novel model. IEEE Access 8: $51884-51904$. https://10.1109/ACCESS.2020.2979822

Ren C, Liang Y J, Lu X J, \& Yan H B (2019). Research on the soil moisture sliding estimation method using the LS-SVM based on multisatellite fusion. International Journal of Remote Sensing 40(5-6): 2104-2119. https://doi.org/10.1080/01431161.2018.1475778

Republic of Turkey Ministry of Agriculture and Forestry (2021). Technical instruction of soil and land classification standards. Retrieved in January, 12, 2021 from https://www.tarimorman.gov.tr/ (In Turkish)

Shamshirband S, Esmaeilbeiki F, Zarehaghi D, Neyshabouri M, Samadianfard S, Ghorbani M A, Mosavi A, Nabipour N \& Chau K W (2020). Comparative analysis of hybrid models of firefly optimization algorithm with support vector machines and multilayer perceptron for predicting soil temperature at different depths. Engineering Applications of Computational Fluid Mechanics 14(1): 939-953. https://doi.org/10.1080/19942060.2020.1788644

Tabari H, Sabziparvar A A \& Ahmadi M (2011). Comparison of artificial neural network and multivariate linear regression methods for estimation of daily soil temperature in an arid region. Meteorology and Atmospheric Physics 110(3): 135-142. https://doi.org/10.1007/s00703-010-0110-z

Turkish State Meteorological Service (2021). Climate status of Izmir province. Retrieved in January, 10, 2021 from https://izmir.mgm.gov.tr/ (In Turkish)

Xing L, Li L, Gong J, Ren C, Liu J \& Chen H (2018). Daily soil temperatures predictions for various climates in United States using datadriven model. Energy 160: 430-440. https://doi.org/10.1016/j.energy.2018.07.004

Yang H, Zhou J, Feng J, Zhai S, Chen W, Liu J \& Bian X (2019). Ditch-buried straw return: A novel tillage practice combined with tillage rotation and deep ploughing in rice-wheat rotation systems. Advances in Agronomy 154: 257-290. https://doi.org/10.1016/bs.agron.2018.11.004

Yener D, Ozgener O \& Ozgener L (2017). Prediction of soil temperatures for shallow geothermal applications in Turkey. Renewable and Sustainable Energy Reviews 70: 71-77. https://doi.org/10.1016/j.rser.2016.11.065

Zhu X \& Goldberg A B (2009). Introduction to semi-supervised learning. Synthesis Lectures on Artificial Intelligence and Machine Learning 3(1): 1-130. https://doi.org/10.2200/S00196ED1V01Y200906AIM006

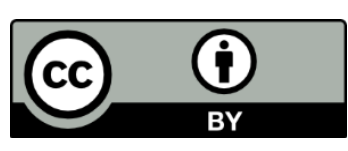

(C) 2022 by the author(s). Published by Ankara University, Faculty of Agriculture, Ankara, Turkey. This is an Open Access article distributed under the terms and conditions of the Creative Commons Attribution (CC BY) license (http://creativecommons.org/licenses/by/4.0/), which permits unrestricted use, distribution, and reproduction in any medium, provided the original work is properly cited. 